\title{
Estimation of electrical resistivity using artificial neural networks: a case study from Lublin Basin, SE Poland
}

\author{
Jakub Ważny $^{1}$ [ $\cdot$ Michał Stefaniuk $^{1} \cdot$ Adam $^{\text {Cygal }}{ }^{1}$
}

Received: 19 September 2020 / Accepted: 6 February 2021 / Published online: 1 March 2021

(c) The Author(s) 2021

\begin{abstract}
Artificial neural networks method (ANNs) is a common estimation tool used for geophysical applications. Considering borehole data, when the need arises to supplement a missing well log interval or whole logging-ANNs provide a reliable solution. Supervised training of the network on a reliable set of borehole data values with further application of this network on unknown wells allows creation of synthetic values of missing geophysical parameters, e.g., resistivity. The main assumptions for boreholes are: representation of similar geological conditions and the use of similar techniques of well data collection. In the analyzed case, a set of Multilayer Perceptrons were trained on five separate chronostratigraphic intervals of borehole, considered as training data. The task was to predict missing deep laterolog (LLD) logging in a borehole representing the same sequence of layers within the Lublin Basin area. Correlation between well logs data exceeded 0.8. Subsequently, magnetotelluric parametric soundings were modeled and inverted on both boreholes. Analysis showed that congenial Occam 1D models had better fitting of TM mode of MT data in each case. Ipso facto, synthetic LLD log could be considered as a basis for geophysical and geological interpretation. ANNs provided solution for supplementing datasets based on this analytical approach.
\end{abstract}

Keywords Artificial neural networks · Well logging · Electrical resistivity $\cdot$ LLD $\cdot$ Magnetotellurics $\cdot$ Parametric sounding · Lublin basin

\section{Introduction}

Artificial neural networks (ANN) are advanced information processing tools, the result of many years of research on artificial intelligence. The basis and inspiration of ANNs and, most importantly - an unsurpassed example, are the human brain. The foundation of study in this field is the work of many researchers-biologists, investigating conditioned reflexes, structure of natural neural networks, the laws of perceiving the external stimuli by nerves, the structure of single neurons and many other biophysical processes. An ANN is a simplified model of the brain, and a single neuron is an incomparable analog of a natural one.

Communicated by Michal Malinowski (CO-EDITOR-INCHIEF) Jadwiga Anna Jarzyna, prof (ASSOCIATE EDITOR).

Jakub Ważny

jwazny@agh.edu.pl

1 AGH University of Science and Technology, Kraków, Poland
Among many merits to using ANNs, two should be stressed-as these features provide for a unique and universally applicable method. The first is the ability for simultaneous information processing. The second and the most important is their ability for self-learning and storing information. Thanks to the latter feature, a properly designed network is able to find a solution for a given calculation problem, even if the network's developer doesn't know the correct answer. ANN's capacity for self-learning, processing and storing implemented signals is strictly connected to their possibilities and applications in prediction and extrapolation of investigated observations.

With a relatively high computational potential, ANNs bring together researchers from various fields and due to their success are commonly used analytical tools for geophysicists. Regarding borehole data, several literature examples describe their applications for well log estimation (Jarzyna et al. 2007; Gąsior et al. 2014; Ważny et al. 2019) and parameters prediction from well logs (Goutorbe et al. 2006; Konaté et al. 2015). 
This paper provides an example of predicting a missing deep laterolog (LLD) logging in a borehole. Five models of neural networks have been used to predict LLD resistivity logging in a SOU1-2 borehole from Lublin Basin area in SouthEastern Poland. The lack of any other resistivity logging in SOU1-2 well has prompted the presented analytical method. As a training data set for networks, well logs from the adjacent SOU1-1 borehole were used.

Five separate models of Multilayer Perceptrons (MLP, Rosenblatt 1957) were trained on subsequent chronostratigraphic intervals. The Multilayer Perceptron is a classical type of neural network. A major advantage of its singular nature is the flexibility to adjust to different binary problems, but the best performance can be obtained when MLPs are used for classification and regression prediction with a supervised learning mechanism. The most suitable form of data for MLP is simply a tabular data set with labels assigned to input signals. Throughout the development of machine learning techniques, MLPs found their place as a basic neural model at the preliminary recognition stage of analysis but also as a versatile predictive tool.

The above method was selected after performing of several different algorithms. Works are available describing the use of others, sometimes more advanced methods with applications in geophysics: support vector machines (SVM, Gholami et al. 2012), recurrent neural networks (RNN, Zhang et al. 2018) and general regression neural networks (GRNN, Rolon et al. 2009). The above mentioned methods are successfully used in geophysical and petrophysical applications.

Facing the given research problem, prediction of a single output from a sequence of inputs, presence of a large set of data in a tabular form, presence of a reference signal in training data set and the need for a relatively low time- and costsconsumptive computational process, the authors decided to choose MLP out of other neural models, obtaining a sufficient result for the geophysical analysis. An additional reason behind the methodology is the fact of one-dimensionality in the described research problem, which makes the whole process less complex.

Statistical verification of prediction was performed on the basis of LLD logging in SOU1-1 well. Based on magnetotelluric parametric soundings data collected near each well, 1D MT modeling and inversion was performed. 1D models were constructed, taking into account $\mathrm{XY}$ and $\mathrm{YX}$ polarization of MT curves and resistivity well logs. 1D Occam inversion resulted in smooth models indicating major resistivity changes, correlation with high-resolution well log data.

\section{Multilayer perceptron neural networks overview}

\section{Single neuron}

The basic element building the network is the neuron (Fig. 1), a system with many inputs receiving signals $x_{i}$, and one output identified with outgoing signal $y$. Inside the body of the neuron there are weighting coefficients $w_{i}$ assigned to the corresponding input signals. The feature of weighting factors, consisting in changes in their values in the learning process, is the special feature of neural networks as adaptive information processing systems. A learning process of single neuron is presented in "Appendix".

\section{MLP neural network}

The Multilayer Perceptron (Rosenblatt 1957; Murtagh 1991) is a type of feedforward network, where the signal travels in one direction from input to output layer. The MLP states as the basic nonlinear neural model, simply described by:

$y=\varphi(e)$

where $\varphi$-activation function, $e-$ value of neuron activation-NET value:

The activation function is the element determining specific network properties, e.g., the type of network's answer. Whereas the $e$ value is responsible for preliminary processing of signals implemented to the network and can be described by:

$e=\sum_{i=0}^{n} w_{i} x_{i}+w_{0}$

The MLP (Fig. 2) consists of: an input layer responsible for receiving input signals, hidden layers that process

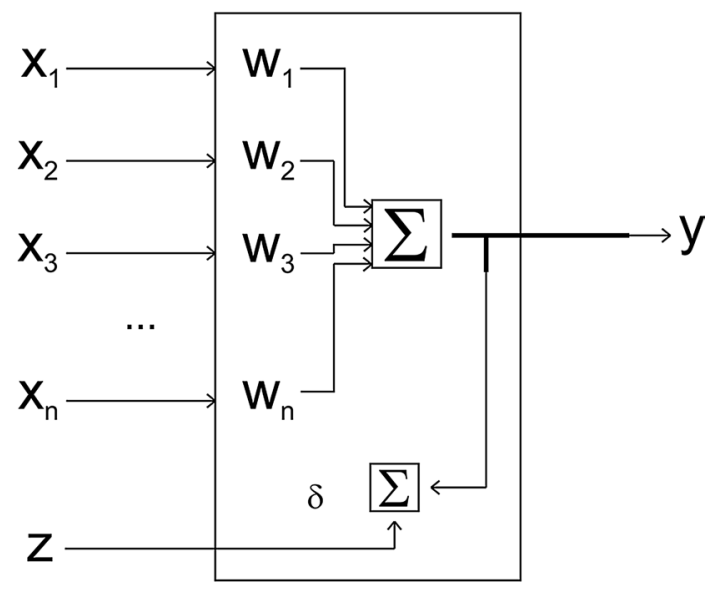

Fig. 1 Simplified scheme of a neuron with Delta learning mechanism 
these signals and an output layer that returns the output information-a result. The number of input layer neurons is connected to the number of types of data. The output layer neurons number is also arbitrary-depends on a number of output data. Hidden layers presence is not necessary, but in the case of complex issues, neurons in this layers pre-processes signals before the final calculation in output layer is performed.

There are several algorithms for training an MLP network. The first proposed algorithm was the backpropagation, invented in the second half of 1980s. Within this paper, authors applied a quasi-Newton, second-derivative-based Broyden-Fletcher-Goldfarb-Shanno (BFGS) algorithm, which is characterized by high stability and low sensitivity on directional minimization errors (Dennis and Schnabel 1983). It attempts to solve a general nonlinear, optimization problem without any constraints at an intermediate and advanced level of complexity. With an optimal number of weights in constructed MLP neural models, it is much faster than backpropagation and does not require large computing resource.

\section{Data source and methodology}

For purposes of the research, well log data of two wells was used: SOU1-1 as a training set for networks and SOU1-2 intended to LLD logging data prediction. A number of five chronostratigraphic intervals from each well was considered separately. On each chronostratigraphic subset, the different MLP neural model was trained. The purpose of this division was to obtain increased accuracy of prediction within the specific environment, as the individual intervals are differentiated with regard to the well logging values. Analysis included Early Devonian $\left(D_{1}\right)$, Early and Late Carboniferous $\left(C_{1}, C_{3}\right)$, Jurassic $(J)$ and Cretaceous $(\mathrm{Cr})$. The well log SOU1-1 training data contained inputs: Depth [m], Chronostratigraphy, DT $[\mu \mathrm{s} / \mathrm{m}]$, RHOB $\left[\mathrm{g} / \mathrm{cm}^{3}\right]$ and GR $[\mathrm{gAPI}]$ with one output: LLD $\left[\Omega^{*} \mathrm{~m}\right]$. It should be stressed, that possibly the use of any other resistivity well logging as input signal would be beneficial for increasing the accuracy of the prediction.

The authors did not have any information regarding additional resistivity well logging in both of the analyzed wells.

Neural networks construction and statistical analysis were performed in module SANN of Tibco Statistica software. Several neural networks for each interval were trained with BFGS algorithm, applying a different architecture, NET
Fig. 2 A structure of multilayered neural network

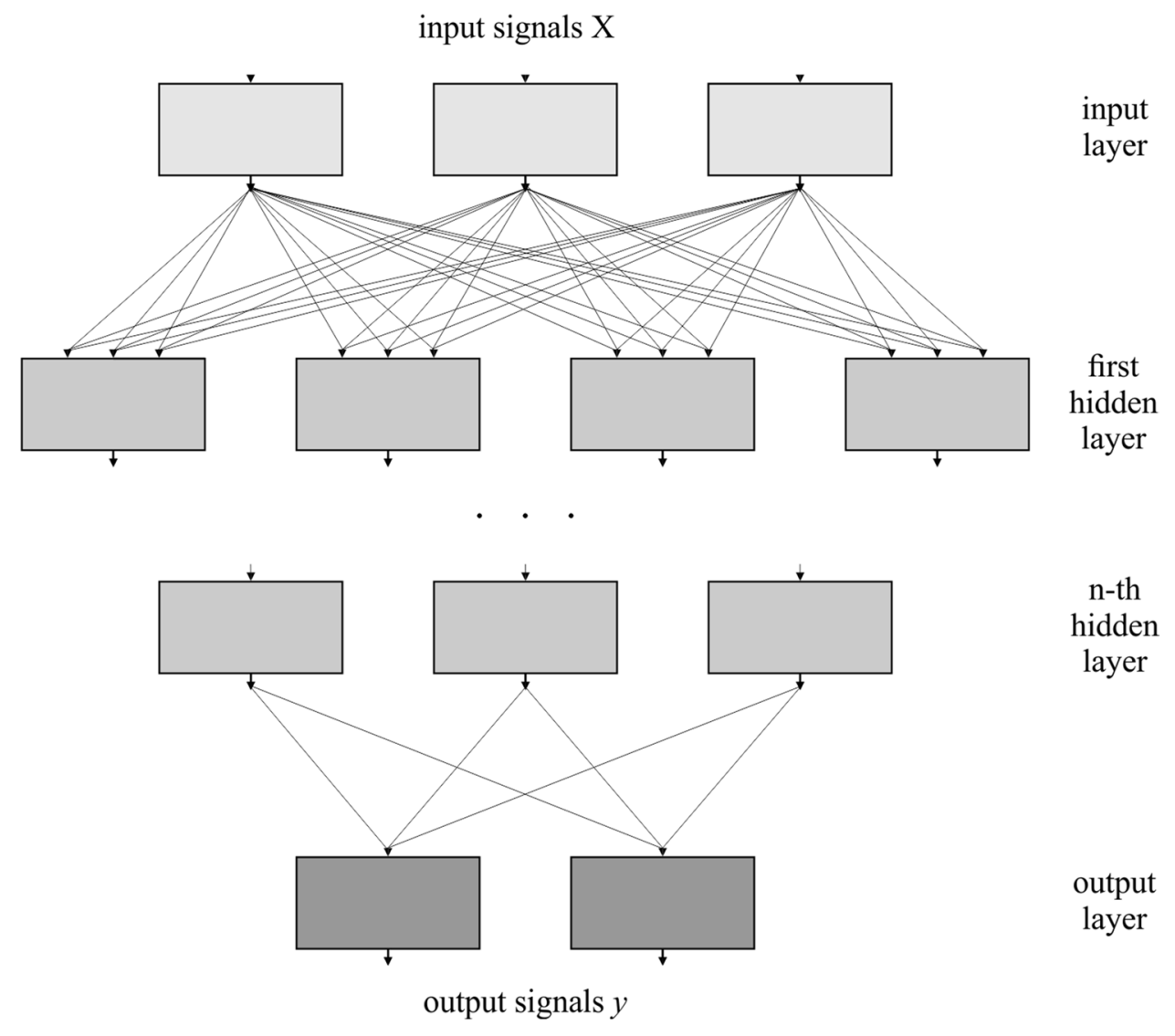


values and activation functions. $70 \%$ of data was used for training, $15 \%$ for validation and $15 \%$ for testing. After training on SOU1-1 data set, five MLP models were selected to predict LLD within each interval of the well. A statistical analysis of measured and predicted LLD values in SOU1-1 was the basis for evaluation the quality of models. In the next step, the authors performed the LLD prediction on unknown SOU1-2 data. The comparison between SOU1-1 well's measured and SOU1-2 well's predicted LLD indicates high similarity of data distribution. The summary of data source and networks architecture is included in Table 1.

\section{Results of prediction: statistical analysis}

A verification of networks prediction in the learning SOU1-1 data set shows strong similarity between each subset-measured and calculated (Table 2). The lowest Pearson's $r$ coefficient reaches value $0.812\left(C_{3}\right)$, the highest value is closer to $1(0.975-\mathrm{Cr})$. Three $r$ values exceed 0.9. As an evidence for the strong linear relationship, Fig. 3 shows scatterplots for each interval. Within four intervals arithmetic means of measured and predicted LLD are equal.

A median parameter, which is less susceptible for any outlier values, shows only small differences between intervals. The highest dissimilarities are noted in the minimum and the maximum, which is connected to single outliers in measured values. Analysis of lower and upper quartile (Q1-25 and Q3-75\% of data set, respectively) shows that

Table 1 Input data type and MLP networks architecture

\begin{tabular}{|c|c|c|c|c|c|c|}
\hline \multirow[t]{2}{*}{ Chronostratigraphic interval } & \multicolumn{2}{|c|}{ Depth interval [m] } & \multirow[t]{2}{*}{ Input data } & \multirow[t]{2}{*}{ MLP architecture* } & \multirow{2}{*}{$\begin{array}{l}\text { NET value } \\
e \text { function }\end{array}$} & \multirow[t]{2}{*}{ Activation function $\varphi$} \\
\hline & SOU1-1 & SOU1-2 & & & & \\
\hline Cretaceous $(\mathrm{Cr})$ & $40-602.9$ & $48-531$ & Depth, DT, RHOB, GR & $4-10-1$ & Tanh & Tanh \\
\hline Jurassic $(J)$ & $603-707.4$ & $531.25-538$ & $\begin{array}{l}\text { Depth, DT, RHOB, } \\
\text { GR, Chronostratig- } \\
\text { raphy }\end{array}$ & $6-6-1$ & Logistic & Logistic \\
\hline Late Carboniferous $\left(C_{3}\right)$ & $707.5-1446.9$ & $616.25-1251$ & DT. RHOB, GR & $3-5-1$ & Tanh & Exponential \\
\hline Early Carboniferous $\left(C_{1}\right)$ & $1447-1614.9$ & $1251.25-1391$ & DT, RHOB, GR & $3-10-1$ & Logistic & Logistic \\
\hline Early Devonian $\left(D_{1}\right)$ & $1615-2421.9$ & $1391.25-1891$ & DT, RHOB, GR & $3-7-1$ & Tanh & Tanh \\
\hline
\end{tabular}

*A MLP architecture should be read as: number of neurons in input layer-number of neurons in hidden layer-number of neurons in output layer, e.g., 4-10-1 stays for 4 neurons in input layer, 10 neurons in hidden layer and one output neuron

Table 2 Basic descriptive statistics values between SOU1-1 measured and predicted LLD with Pearson's $r$ correlation coefficient and predicted values in SOU1-2 well

\begin{tabular}{|c|c|c|c|c|c|c|c|c|c|}
\hline LLD dataset & Period & Pearson's $r$ & Arithmetic mean & Median & Minimum & Maximum & $Q 1$ & $Q 3$ & Std. dev \\
\hline SOU1-1 measured & \multirow[t]{3}{*}{ Cretaceous $\mathrm{Cr}$} & \multirow[t]{2}{*}{0.975} & 1.415 & 1.435 & 0.151 & 2.122 & 1.310 & 1.536 & 0.182 \\
\hline SOU1-1 predicted & & & 1.415 & 1.438 & 0.117 & 2.107 & 1.307 & 1.527 & 0.177 \\
\hline SOU1-2 predicted & & - & 1.473 & 1.440 & 1.149 & 1.824 & 1.395 & 1.562 & 0.125 \\
\hline SOU1-1 measured & \multirow[t]{3}{*}{ Jurassic $J$} & \multirow[t]{2}{*}{0.943} & 2.079 & 2.095 & 1.397 & 2.753 & 1.926 & 2.231 & 0.242 \\
\hline SOU1-1 predicted & & & 2.079 & 2.098 & 1.414 & 2.734 & 1.947 & 2.219 & 0.22 \\
\hline SOU1-2 predicted & & - & 1.922 & 1.950 & 1.409 & 2.602 & 1.826 & 2.029 & 0.192 \\
\hline SOU1-1 measured & \multirow[t]{3}{*}{ Late Ccarboniferous $C_{3}$} & \multirow[t]{2}{*}{0.812} & 1.490 & 1.501 & 0.689 & 3.150 & 1.325 & 1.645 & 0.273 \\
\hline SOU1-1 predicted & & & 1.490 & 1.509 & 0.912 & 2.820 & 1.374 & 1.591 & 0.223 \\
\hline SOU1-2 predicted & & - & 1.506 & 1.532 & 1.014 & 3.278 & 1.388 & 1.600 & 0.212 \\
\hline SOU1-1 measured & \multirow{3}{*}{$\begin{array}{l}\text { Early Ccarboniferous } \\
C_{1}\end{array}$} & \multirow[t]{2}{*}{0.951} & 1.451 & 1.259 & 0.645 & 3.405 & 1.070 & 1.533 & 0.580 \\
\hline SOU1-1 predicted & & & 1.442 & 1.242 & 0.786 & 2.936 & 1.097 & 1.432 & 0.543 \\
\hline SOU1-2 predicted & & - & 1.653 & 1.452 & 0.740 & 3.110 & 1.194 & 1.990 & 0.580 \\
\hline SOU1-1 measured & \multirow[t]{3}{*}{ Early Devonian $D_{1}$} & \multirow[t]{2}{*}{0.875} & 1.139 & 1.199 & 0.595 & 1.812 & 0.906 & 1.333 & 0.256 \\
\hline SOU1-1 predicted & & & 1.139 & 1.205 & 0.640 & 1.634 & 0.892 & 1.313 & 0.224 \\
\hline SOU1-2 predicted & & - & 1.123 & 1.158 & 0.676 & 1.686 & 0.896 & 1.297 & 0.213 \\
\hline
\end{tabular}



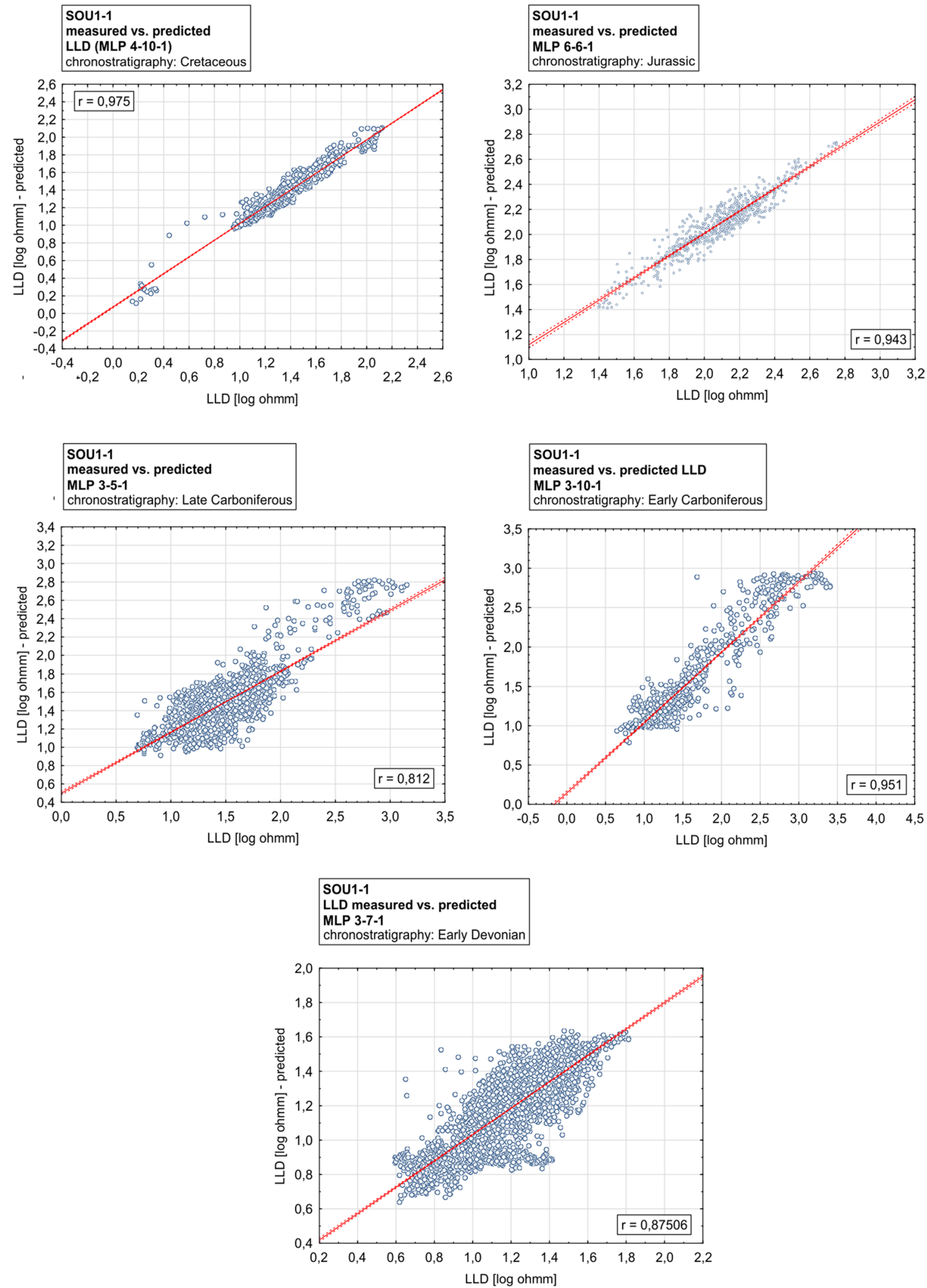

Fig. 3 Scatterplots between measured and predicted values of LLD in SOU1-1 well (training dataset) 
the distribution of values in measured and predicted subset in each chronostratigraphic interval of SOU1-1 is more than similar.

After verification of each neural model within the known data set, networks were used to predict LLD values on new data, with use of input signals having their origin in SOU1-2 well logging: DT traveltime, RHOB, GR, Depth and Chronostratigraphy (Table 1). Regarding the same chronostratigraphic layers sequence and the same geological conditions, and taking into account that well logging was performed with use of the same techniques, a properly evaluated set of synthetic values should present similar distribution across each interval.

Statistical analysis results are presented on Fig. 4. Based on imposed histograms, the first thing that should be noticed is a crucial difference in the observations number (histograms, Fig. 4). Orange bars (SOU1-2) in each case present lower observation values. The reason lies in two issues: each chronostratigraphic interval of SOU1-2 is of smaller thickness, compared to SOU1-1. The second issue is that in SOU1-1 the sampling interval is equal to $0.1 \mathrm{~m}$, where in SOU1-2 it is $0.25 \mathrm{~m}$. However, analysis of histograms indicates that in each class the trend remains similar-which provides evidence that the distribution across the classes is proportional. To have better view on the values within each interval, on the right side of histograms box plots are presented. The most significant differences are observed in two cases: maximum values in Cretaceous-almost $0.4 \mathrm{log}$ ohmm and Q3 value in Early Carboniferous - 0.5 log ohmm. Other values differences do not exceed $0.2 \mathrm{log}$ ohmm. The quantitative analysis of plots should be supplemented with values included in Table 2, where statistics of predicted data in SOU1-2 are included. What should be stressed is, that the neural models in individual intervals reliably predicted complex subsets structure, e.g., domination of two classes in Late Carboniferous and bimodal distribution in early devonian.

To present more accurately the similarity between measured and predicted values in each well, the imposed histogram and box plot were constructed for whole depth intervals (Fig. 5), and the results were promising. Based on histograms analysis, the observations number in each well differs, nevertheless trends across the classes suggest a similar distribution. This fact is confirmed by box plots (Fig. 5, right side): the median, quartiles, minimum and maximum values are equal with nearly $0.1 \mathrm{log}$ ohmm of tolerance.

In the last step of analysis on measured and predicted LLD values between wells, parameters were plotted in depth domain as well logs, with distinction of each chronostratigraphic interval (Fig. 6). Trends changes are strictly connected with lithology differentiation within layers, and this occurs in both wells profiles. In Cretaceous, LLD sensor reading fluctuations are well predicted as synthetic log with values around $1.5 \mathrm{log}$ ohmm. Jurassic is marked as highly resistive, thin layer. Unstable reading in Late Carboniferous with many outlier values are present in both logs, with a median of $1501 \mathrm{log}$ ohmm for SOU1-1 and $1532 \mathrm{log}$ ohmm for SOU1-2 (Table 2). The Early Carboniferous is the most differentiated layer and also, from the point of ANN training - a subset with the lowest qualitative evaluation $(r=0812$, Table 2$)$ and the lowest prediction results with median difference 0.2 and Q3 difference of $0.5 \mathrm{log}$ ohmm. The reason for it is strong differentiation with many picks and outliers. The subset is characterized by strong domination of one class of observations in the SOU1-1 well, which is not clearly reflected in the prediction results. Considering Early Devonian, in both cases values fluctuate between 1 and 1.5 log ohmm with median 1199 for SOU1-1 and 1158 for SOU1-2. Importantly, the prediction results reflect resistivity change within interval: from $2100 \mathrm{~m}$ in measured values and $1700 \mathrm{~m}$ in synthetic log.

\section{Magnetotelluric parametric soundings: a geophysical verification}

The geoelectric section can be characterized by reducing multiple layers of the model to one equivalent layer using the concept of total longitudinal conductivity and total transverse resistivity. The methodology assumes building a model based on the electric sounding resistivity log in the borehole. The well log consists of many (thousands) layers. The number of these layers can be effectively reduced to a few equivalent layers. This method is based on the fact that the group of electromagnetic methods is sensitive only to good conductors. Therefore, the sum longitudinal conductivity curve is used to generalize the electrical resistivity well log.

The IX1D.v3 software from Interpex Limited was used to perform a detailed interpretation of the parametric soundings in SOU1-1 and SOU1-2 wells by the 1D Occam inversion method (Constable et al. 1987). The input data is displayed in the form of a curve in which the resistivity values are averaged by arranging them into ranges corresponding to the specified resistivity limits. The correctness of the model is determined by the best fit of the averaged sections of resistivity to the total longitudinal conductivity curve. It should be noted that while electromagnetic methods are sensitive only to conductive layers, all methods based on resistivity are sensitive to both-including conductivity. Consequently, they assume an intrinsic anisotropy of the layers. The IX1D program is addressed only to isotropic models, therefore the reduction of 1D layers on the basis of well logging data will be limited to the use of the total longitudinal conductivity.

In the next step, the model with reduced number of equivalent layers is juxtaposed with MT sounding curves of apparent resistivity and phase. Properly performed modeling 
Fig. 4 Statistical comparison of measured LLD values in SOU1-1 well and predicted LLD values in SOU1-2 well; the different measurement step and thickness of individual intervals causes a difference in observations number between blue and orange bars
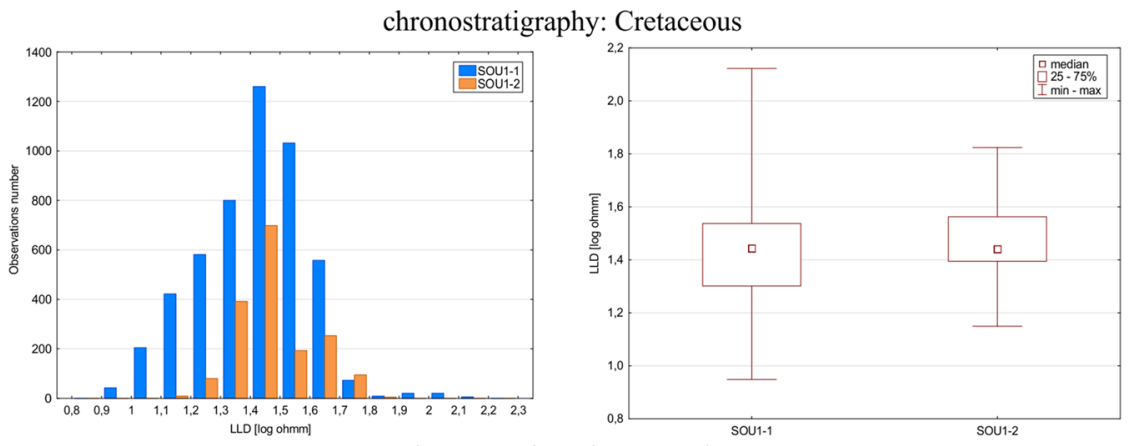

chronostratigraphy: Jurassic
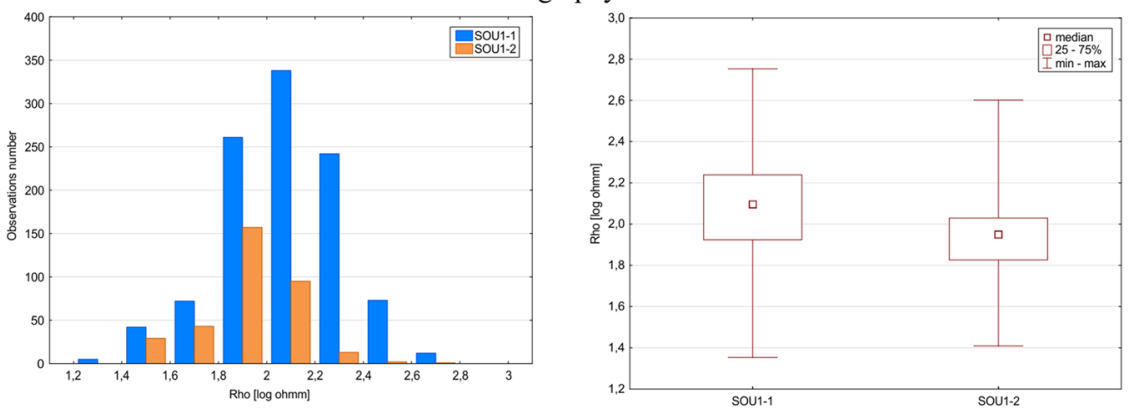

chronostratigraphy: Late Carboniferous
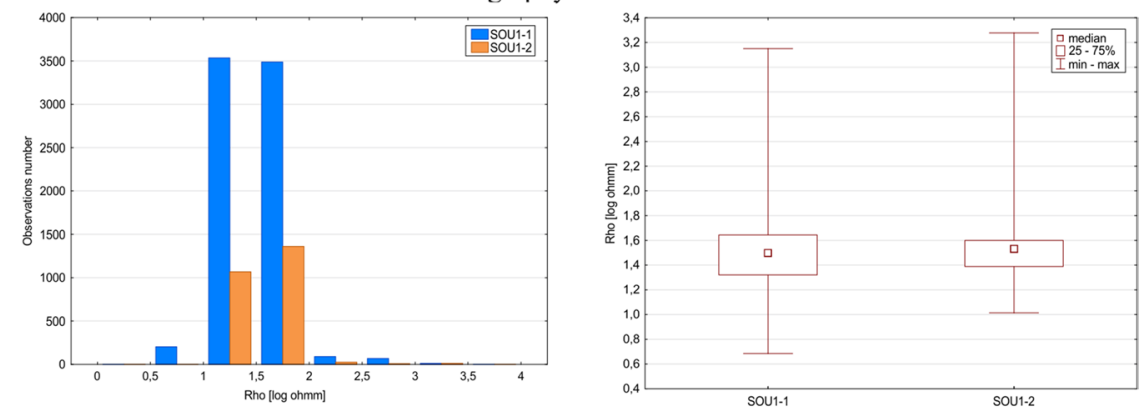

chronostratigraphy: Early Carboniferous
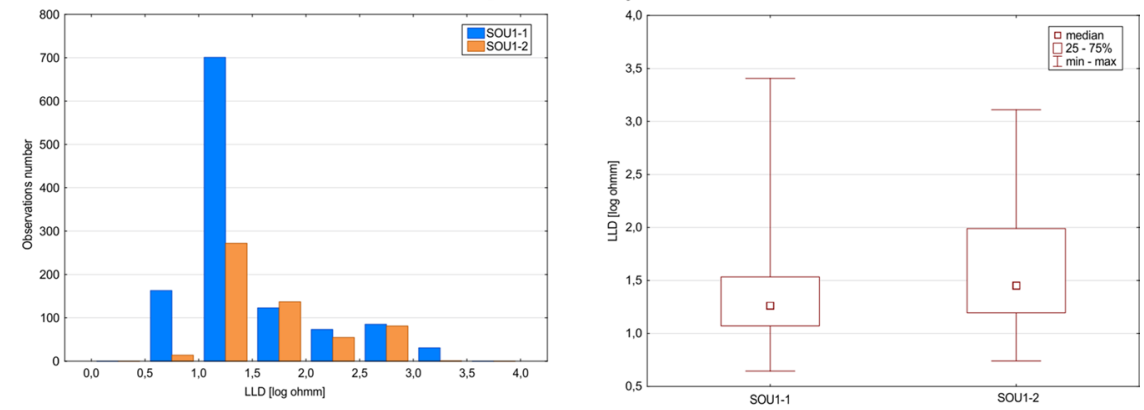

chronostratigraphy: Early Devonian
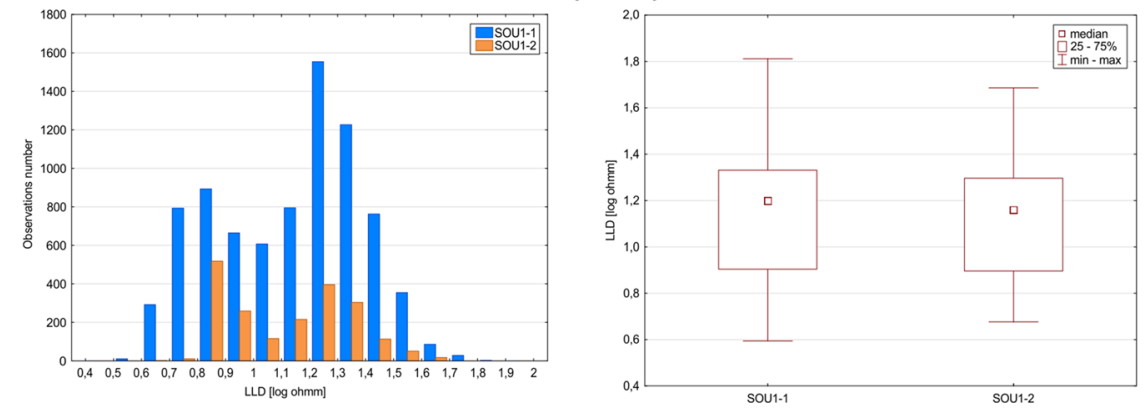

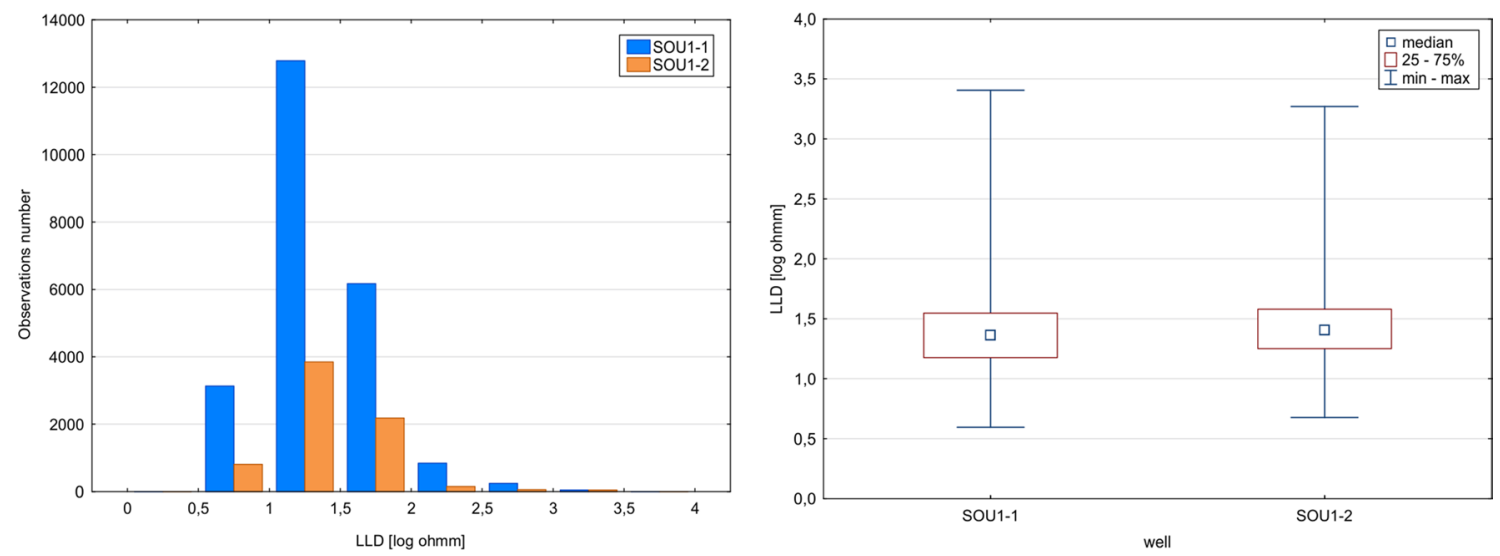

Fig. 5 Histograms and box plots for complete profiles of SOU1-1 and SOU1-2 wells; the different measurement step and thickness of individual intervals causes a difference in observations number between blue and orange bars

Fig. 6 Well $\log$ of measured values of LLD in SOU1-1 well (left side) and predicted LLD values in SOU1-2 well (right side)

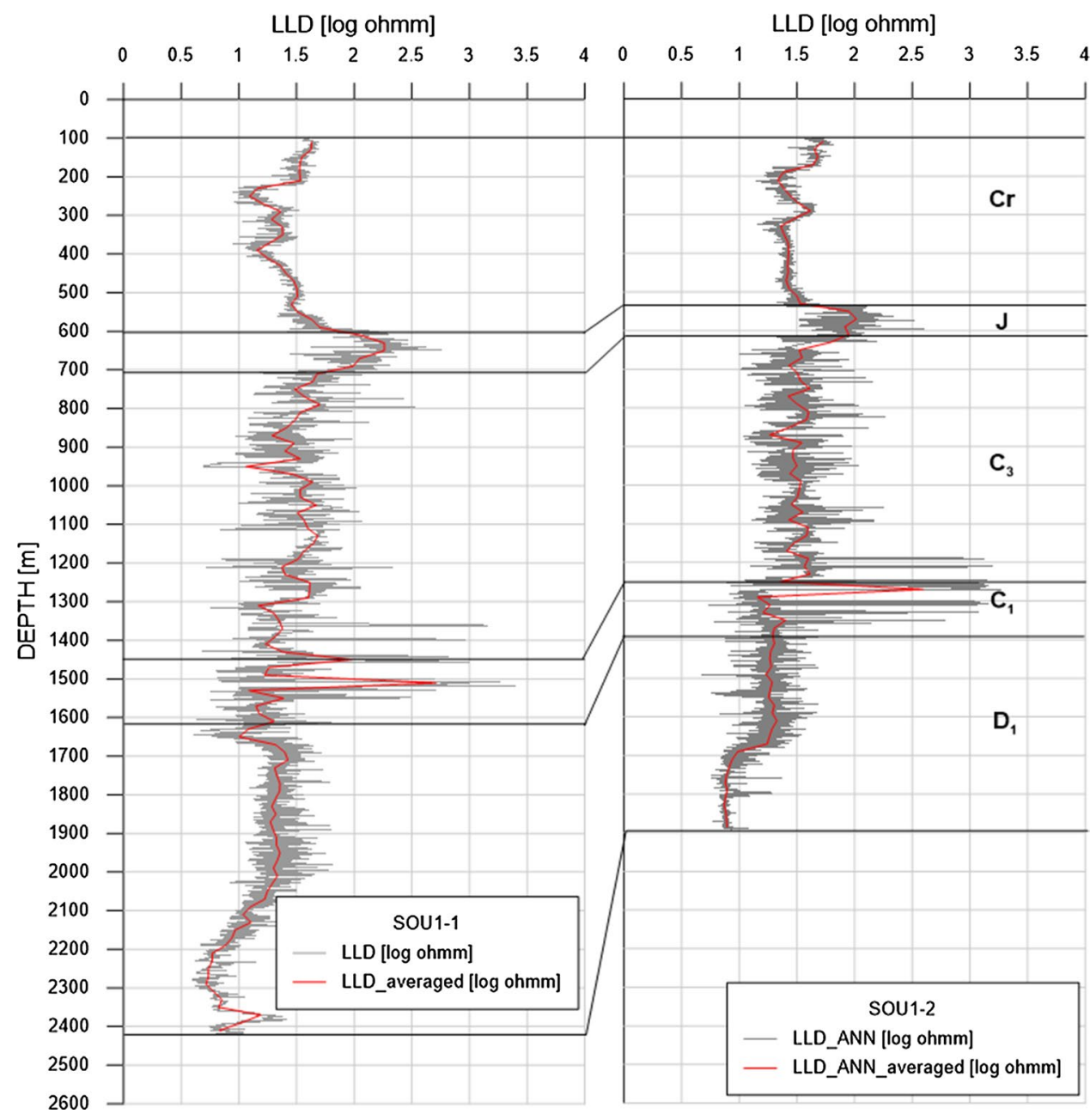

should imitate the shape of apparent resistivity MT curve. With small modifications, modeling should seek to obtain an optimal solution between well log and MT curve. The effect is presented on Fig. 7. The solid violet line is fitted to magnetic polarization (XY) curve of magnetotelluric data for both boreholes (SOU1-1—left side, SOU1-2—right side), taking into account changes in LLD readings in a well.

The created model states as a basis for 1D Occam inversion, and the results are shown as green lines on Fig. 7. The algorithm calculates the effect on the curve and in a 

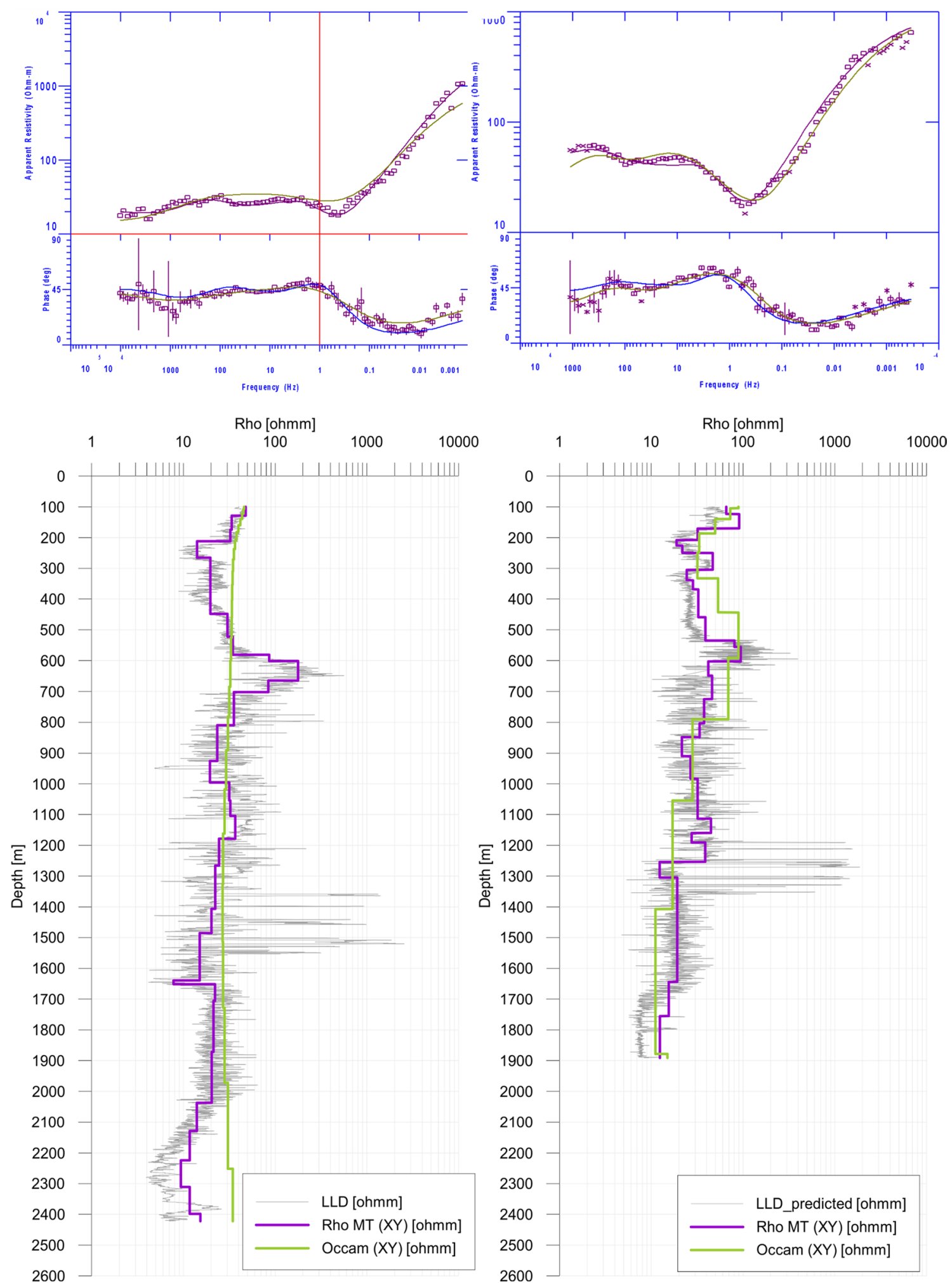

Fig. 7 Parametric sounding results on SOU1-1 well (left side) and SOU1-2 well with predicted LLD values (right side) for magnetic

based on MT XY curve: violet line-starting model, green line-1D Occam inversion result; lower parts: modeling and inversion results with LLD well logs 
borehole pathway. The feature of Occam inversion is, that the resulting model presents a smooth resistivity distribution. The resolution of MT method is incomparably lower than well logging. Thus, obtained 1D models are in a form of even more generalized curves than equivalent starting ones. Especially for SOU1-1 well, the obtained resolution is low. The Occam inversion model presents very general resistivity changes. It correlates with borehole logging but does not take into account subtle resistivity changes in Jurassic. Furthermore, it generalizes all Carboniferous and is no sensitive to low resistive Devonian layer. For SOU1-2, the authors managed to.

obtain an inversion model characterized by a higher resolution, without major errors and discrepancy between the well log and MT curve, with projection of minor resistivity fluctuations in Jurassic and separation of Early and Late Carboniferous.

\section{Discussion}

Prediction based on artificial neural networks is of high quality. In the authors opinion, in the case of predicting the geophysical parameters throughout the borehole profile, better results are obtained by separating the analysis between chronostratigraphic intervals. Preliminary research assumed the use of one model, which resulted in less differentiated LLD well $\log$ in SOU1-2. Furthermore, the statistical analysis indicated high differences between measured and predicted data sets. Creating five different networks and treating each layer individually allowed for more flexible analysis with regard of utilization several input signals schemes, adjusting hidden layer neurons number to complexity of prediction and applying the best activation functions to the individual features of each layer. Every chronostratigraphic interval was described by the change of DT travel time, density and contamination of shale element influencing gamma ray readings. These parameters differ depending on lithology changes. As a result of the individual approach, prediction was performed with the lowest $r$ coefficient exceeding 0.8 and the highest equal to 0.97 . Between SOU1-1 and SOU1-2 data sets the most important feature, the distribution structure, is highly comparable with a natural difference only in observations number which does not affect the result (Fig. 4 and 5).

Physical properties of geological medium such as elastic properties, bulk density and natural radioactivity, described, respectively, by DT, RHOB and GR well logs affect the influence of LLD readings in the same way in specific geological conditions. In terms of similar methodology of well log data collecting, the conclusion is that within this research a set of artificial neural networks for LLD prediction in Lublin Basin area's chronostratigraphic intervals was constructed. This is an additional effect to the final result-a correctly performed prediction of LLD in SOU1-2 borehole.

The above statement, based on analytical verification, is later confirmed by physical measurement on a borehole with use of magnetotelluric soundings. Both data sets are characterized by different resolution, nevertheless MT soundings are commonly fixed to borehole data, and the basis for such methodology is looking for trends changes between borehole and cross-section. What is important, 1D Occam inversion model is highly correlated with synthetic data, which allows for the consideration of artificial neural network-based well logging as a reliable basis for further geophysical and geological interpretation with use of 2D surface-collected geophysical data.

\section{Conclusion}

Within this paper, the authors presented the issues related to lack of geophysical well logging. Applications of artificial intelligence are nowadays commonly and broadly used in petrophysical research and well logging data interpretation. Successively these methods displace classical analytical ones by getting the result relatively fast and by unifying interpretation algorithms.

The aim of the performed research was to verify the use of artificial neural networks in processing of magnetotelluric data. The problem of MT data interpretation is the high equivalence phenomenon, which if not controlled, can lead to incorrect geoelectric imaging results. This effect can be limited by using the inversion procedure with constraintsan additional information that allows stabilizing the model in terms of depth and resistivity.

The use of statistical methods allows for calibration and often supplementing the missing information in well data sets, which was presented in this paper. It should be noted that the use of this methodology entails the possibility of introducing errors resulting from ambiguities in estimating procedures. However, the article presented that the estimated LLD resistivity values, based on the available well logging data, are useful and determined by lithology. The correctness of these results is local and can be applied mainly to the lithology of geological formations, but in a local area it allows to increase the amount of a priori information that can be successfully used in the process of magnetotelluric data inversion and even for the construction of velocity models as the so-called bonds. In the article, estimates were made in the Lublin Basin, where the general conditions are relatively simple, and the analyzed wells were within the same geological and tectonic units.

The obtained data set was verified with the use of simple and inverse magnetotelluric data modeling. The use of the starting model, which was built on the basis of the 
estimate of the resistance curve for the SOU1-2 well, resulted in a very good fit of the model to the real data. It allows the authors to believe in the applied procedure. The methodology can be used in spatial analyses which may require more advanced statistical procedures. The obtained results suggest that this methodology will be useful in geological mediums with a high degree of tectonic deformation, for example in the Eastern Carpathians, where the amount of well logging information is much lower than the number of geophysical surveys performed.

A Multilayer Perceptron with quasi-Newton BFGS algorithm turned out to be stable and sufficient solution for a given analytical problem. On the basis of prediction results performed on unknown set of data-SOU1-2 well, MLPs were evaluated as correct models. The authors managed to avoid an overfitting phenomenon causing very good prediction on training data, but presenting inaccurate results on new data. In the authors opinion, prediction in a one-dimensional geophysical environment, i.e., well data, Multilayer Perceptron states as a very good predicting tool with stable results and time efficiency. Obviously, as mentioned above, the application of created neural model should be performed with awareness on geological changes across the research area and the technical limitations of the method.

\section{Nomenclature}

Artificial neural network (ANN) -a general name of mathematical structure and its model inspired by simplification of a biological brain; ANN is composed of multiple nodes, which imitate biological neurons. These nodes or artificial neurons, are connected by links and they interact with each other. Within neuron body a simple operation on the data is performed, and the result of this operations is passed to subsequent layers and their neurons within model. Neuron body itself is equipped with weighting mechanism that adjusts to input data as learning process proceeds. The coefficient increases or decreases the strength of the signal at a connection. The output at each neuron is called the activation value. The value that goes out from the neuron in output layer is a resulting answer of a network.

Multilayer Perceptron - the basic and the most popular model of a neural network elaborated by Frank Rosenblatt in 1957. It usually consists of at least three layers: an input layer, hidden layer and an output layer. It is a kind of feedforward network, where the signal travels in one direction from input to output layer. Except for the input nodes, each node is a neuron that uses a nonlinear activation function. It uses a supervised learning method.
Input layer - a first layer of neurons that brings an initial data to the structure of a network. The number of neurons in input layer corresponds to the number of input data in training set.

Hidden layer — located between input and output layer of the model. The input signal coming into the hidden neurons is differentiated by assigning weights and then through an activation function goes out as an output. The hidden neurons perform a nonlinear transformations of input signals implemented to the network.

Output layer -is responsible for producing the final result. There must always be one output layer in a neural network. The output layer takes in the inputs which are passed in from the layers before it (hidden layers), performs the calculations via its neurons and then the output is computed.

\section{Appendix}

A learning process is performed by changing values of weights inside the neuron body, aiming iteratively to minimize the mean square error (Tadeusiewicz 1993):

$Q=\frac{1}{2} \sum_{j=1}^{\mathrm{N}}\left(z^{(j)}-y^{(j)}\right)^{2}$

where:

$y^{(j)}=\varphi\left(\sum_{i=0}^{\mathrm{n}} w_{i}^{(j)} x_{i}^{(j)}\right)$

According to (1), mean square error in $j$-th learning step is given by:

$Q^{(j)}=\frac{1}{2}\left(z^{(j)}-y^{(j)}\right)^{2}$

Taking above into account, the algorithm of weight coefficients changes is given by:

$\Delta w_{i}^{(j)}=-\eta \frac{\partial Q^{(j)}}{\partial w_{i}}$

Dependence of output signal from weight coefficient is connected to nonlinear function $\varphi(e)$ :

$\frac{\partial Q^{(j)}}{\partial w_{i}}=\frac{\partial Q^{(j)}}{\partial y^{(j)}} \frac{\partial y^{(j)}}{\partial w_{i}}=\frac{\partial Q^{(j)}}{\partial y^{(j)}} \frac{\mathrm{d} y^{(j)}}{\mathrm{d} e^{(j)}} \frac{\partial e^{(j)}}{\partial w_{i}}$

The derivative of the first and last factor of expression (5) is, respectively: $-\delta^{(j)}$ and $x_{i}^{(j)}$. The problem occurs with the middle factor since $y=\varphi(e)$ is not always differentiable. Thus, functions with simple derivatives, e.g., logistic 
function or hyperbolic tangent (Tanh), are eagerly used. The final formula for training a nonlinear network neuron can be written as (Tadeusiewicz 1993):

$\Delta w_{i}=\eta \delta^{(j)} \frac{\mathrm{d} \varphi(e)}{\mathrm{d} e^{(j)}} x_{i}^{(j)}$

Acknowledgements Results are based on investigation carried out within the framework of projects: Bluegas I no.17.17.140.86680 and statutory grant no. 16.16.140.315/05.

\section{Compliance with ethical standards}

Conflict of interest On behalf of all authors, the corresponding author states that there is no conflict of interest.

Open Access This article is licensed under a Creative Commons Attribution 4.0 International License, which permits use, sharing, adaptation, distribution and reproduction in any medium or format, as long as you give appropriate credit to the original author(s) and the source, provide a link to the Creative Commons licence, and indicate if changes were made. The images or other third party material in this article are included in the article's Creative Commons licence, unless indicated otherwise in a credit line to the material. If material is not included in the article's Creative Commons licence and your intended use is not permitted by statutory regulation or exceeds the permitted use, you will need to obtain permission directly from the copyright holder. To view a copy of this licence, visit http://creativecommons.org/licenses/by/4.0/.

\section{References}

Constable S, Parker RL, Constable CG (1987) Occam's inversion: a practical algorithm for generating smooth models from electromagnetic sounding data. Geophysics 52(3):289-300

Dennis JE, Schnabel RB (1983) Numerical methods for unconstrained optimization and nonlinear equations. Prentice-Hall, Englewood Cliffs NJ
Gardner GHF, Gardner LW, Gregory AR (1974) Formation velocity and density - the diagnostic basics for stratigraphic traps. Geophysics 39(6):770-780. https://doi.org/10.1190/1.1440465

Gąsior I, Reicher B (2014) Estymacja czasu interwałowego z profilowań geofizyki otworowej metodą sieci neuronowych. NaftaGaz 11(2014):765-770

Gholami R, Sharaki A R, Paghaleh J (2012) Prediction of hydrocarbon reservoirs permeability using support vector machine. Math Probl Eng 2012

Goutorbe B, Lucazeau F, Bonneville A (2006) Using neural networks to predict thermal conductivity from geophysical well logs. Geophys J Int 166:115-125. https://doi.org/10.1111/j.1365246X.2006.02924.x

Jarzyna J, Oprychał A, Mozgowoj D (2007) Sztuczne sieci neuronowe dla uzupełnienia danych w geofizyce otworowej-wybrane przykłady. Geologia 33(4/1):81-102

Konaté AA, Pan H, Khan N, Yang JH (2015) Generalized regression and feed-forward back propagation neural networks in modelling porosity from geophysical well logs. J Pet Explor Prod Technol 5:157-166. https://doi.org/10.1007/s13202-014-0137-7

Murtagh F (1991) Multilayer perceptrons for classification and regression. Neurocomputing 2(5-6):183-197

Rolon L, Mohaghegh SD, Ameri S, Gaskari R, McDaniel B (2009) Using artificial neural networks to generate synthetic well logs. J Nat Gas Sci Eng 1(4-5):118-133

Rosenblatt F (1957) The Perceptron-a perceiving and recognizing automaton. Tech Report 85-460-1. Cornell Aeronaut Lab

Tadeusiewicz R (1993) Sieci neuronowe. Akademicka Oficyna Wydawnicza RM, Warszawa

Ważny J, Cygal A, Stefaniuk M (2019) Application of artificial neural networks to develop input data for acoustic and elastic inversion in the Wysin 1 well and for part of the Wysin-3D seismic image. CAGG-AGH-2019 [electronic document]: challenges in applied geology and geophysics: 100th anniversary of applied geology at agh university of science and technology: international scientific conference: 10-13 September 2019, Kraków: book of abstracts 169-170 http://www.cagg2019.agh.edu.pl/Book\%20of\%20Abs tract\%20pdf\%20only/9\%20Poster\%20session/Wa\%C5\%BCny\%20 et\%20al.pdf

Zhang D, Chen Y, Meng J (2018) Synthetic well logs generation via recurrent neural networks. Pet Explor Dev 45(4):629-639 